\title{
CORRELATION BETWEEN CUTTING TEMPERATURES AND METALLURGICAL PROPERTIES OF COMPACTED GRAPHITE CAST IRONS IN THE END MILLING PROCESS
}

\author{
L. R. R. da Silva $a^{a, b}$, \\ and A. R. Machado ${ }^{a, b}$ \\ ${ }^{a}$ Federal University of Uberlandia, \\ School of Mechanical Engineering, \\ Av. João Naves de Ávila, 2121, Bloco 1M, \\ 38400-902, Uberlândia, MG, Brazil. \\ leorrs@ufu.br \\ ${ }^{\mathrm{b}}$ Graduate Program in Mechanical \\ Engineering, Pontifícia Universidade Católica \\ do Paraná - PUC-PR, R. Imaculada \\ Conceição, 1155, Bairro Prado Velho, CEP \\ 80215-901, Curitiba/PR, Brasil. \\ alisson.rocha@pucpr.br
} Received: Jun 14, 2021 Revised: Jun 16, 2021 Accepted: Jun 20, 2021

\section{ABSTRACT}

In the search for more energy-efficient internal combustion engines, the automotive companies keep pushing the working temperatures and pressures of the engines, leading to more extreme working conditions and so the necessity of new materials. Among the most promising materials for the new generations of engines is the compacted graphite cast iron, which is more wear-resistant than aluminum and tougher than gray cast iron. However, this combination of properties also leads to decreased machinability, increasing production costs and, therefore, their market competitiveness. This paper evaluated the correlation of mechanical and metallurgical properties and the cutting power and surface roughness of three grades of compacted graphite cast iron with the cutting temperature in the end milling process under different two different feed rates and cutting speeds. This analysis showed that the temperatures near the cutting zone are closely correlated to the material's mechanical properties, machining power, and resulting roughness. These results indicate that thermographic images are a good indicator of the overall correlation between the changes in material properties and the most usual machinability output parameters.

Keywords: machining temperatures, compacted graphite cast irons, thermographic monitoring, mechanical and metallurgical properties

\section{INTRODUCTION}

Aiming both to save fossil fuels and reduce the emission of pollutants, the demand for greater energy efficiency in internal combustion engines grows every year. According to Dawson (2008), the key to improving efficiency is higher compression ratios in the engines, thus resulting in better performance.

Nodular and compact/vermicular graphite (CGI) cast irons were discovered simultaneously in 1948 and patented in 1949. Notably, the discovery of CGI occurred by accident during the invention of the nodular cast iron, with CGI being initially considered a degraded form of the nodular cast iron (Murthy and Seshan, 1985). Even though efforts were made until the 1980s to improve CGI's large-scale production techniques (Estes and Schneidewind, 1955), only from the $90 \mathrm{~s}$ did the production of CGI reach levels comparable to those of gray cast iron, mainly motivated by the production of supercharged engine blocks in Europe (Dawson and Indra, 2007).

Due to the combination of characteristics, the biggest fields of application of CGI are projects that require materials with mechanical properties superior to those of gray cast iron, combined with superior vibration and heat dissipation capacity than that of nodular cast iron (Dawson and Schroeder, 2004). When compared to gray cast iron and aluminum alloys, CGI has mechanical properties that allow for improvements over engine manufacturing, such as decreased mass and increased peak pressures along with greater wear resistance (Guesser et al., 2004). Recent advances have been made to use these materials in other automotive components subject to intense wear and thermal fatigue, such as exhaust manifolds (Guesser and Guedes, 1997) and brake elements (Lim and Goo, 2011). The optimization of these factors is usually associated with energy efficiency gains and reduction in the emission of pollutants, which increases the sustainable appeal of this material (da Silva et al., 2021).

Due to the inherent complexity of machining processes, it is virtually impossible to predict the machinability of a system (Shaw, 1984). The superior mechanical properties of CGI in relation to aluminum and gray cast iron make the machining of this material a challenge, with this lower machinability being evidenced in the turning processes (Da Silva et al., 2020). 
This work aims to evaluate the correlation between the machining temperature with the mechanical and metallurgical properties, as well as with the machining power and surface roughness of three compacted graphite cast irons, one (CGI A) class 450 and the other two (CGIs B and C) of class 500.

\section{MATERIALS AND METHODS}

This work evaluates three different compact graphite cast iron (CGI) intended to produce highperformance internal combustion engines. These materials were named CGI A, CGI B, and CGI C, with a similar chemical composition of $4.2 \%$ carbon equivalent $(\mathrm{C}+\mathrm{Si} / 3+\mathrm{P} / 3)$, and a $0.9 \% \mathrm{Cu}$ and a $0.07 \%$ $\mathrm{Sn}, 0.1 \% \mathrm{Mo}$ is added to the CGI C. The microstructures of the materials are illustrated using optical microscopy in Fig. 1, showing that both CGIs $\mathrm{B}$ and $\mathrm{C}$ have more refined graphite verms.

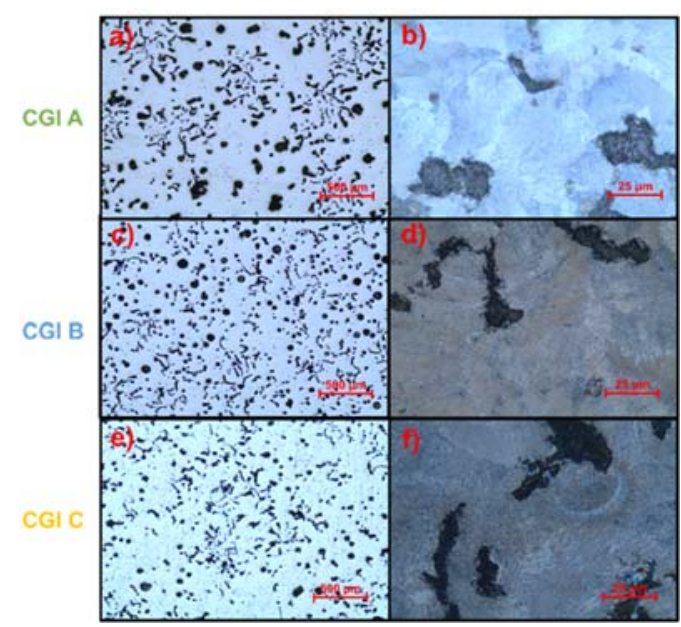

Figure 1. Microstructures of the materials evaluated. The lower figures are larger magnifications of the samples after attacks (Nital-2\% for 15 seconds).

Adapted from da Silva et al. (2018).

Figure 2 illustrates the mechanical properties of the evaluated materials. Figure 2.a illustrates the graphite classification by metallographic analysis, performed according to ISO-945 (2011). Figure 2.b shows the tensile tests for the materials evaluated, based on the ISO-16112 (2017) standard. Figure 2.c illustrates the Brinell hardness values, also performed according to the ISO-16112 (2017) standard. Figure 2.d illustrates the Vickers microhardness of the matrices of the materials evaluated, as well as that of the CGI C carbides, which have, on average, hardness more than 3.5 times greater than the matrix. The lower hardness of the CGI A matrix in relation to other materials can be explained based on Fig. 2e, which illustrates the average interlayer spacing of the materials studied, measured as indicated by Vander Voort (1999). Figure 2.f illustrates the Charpy impact toughness of the materials evaluated.

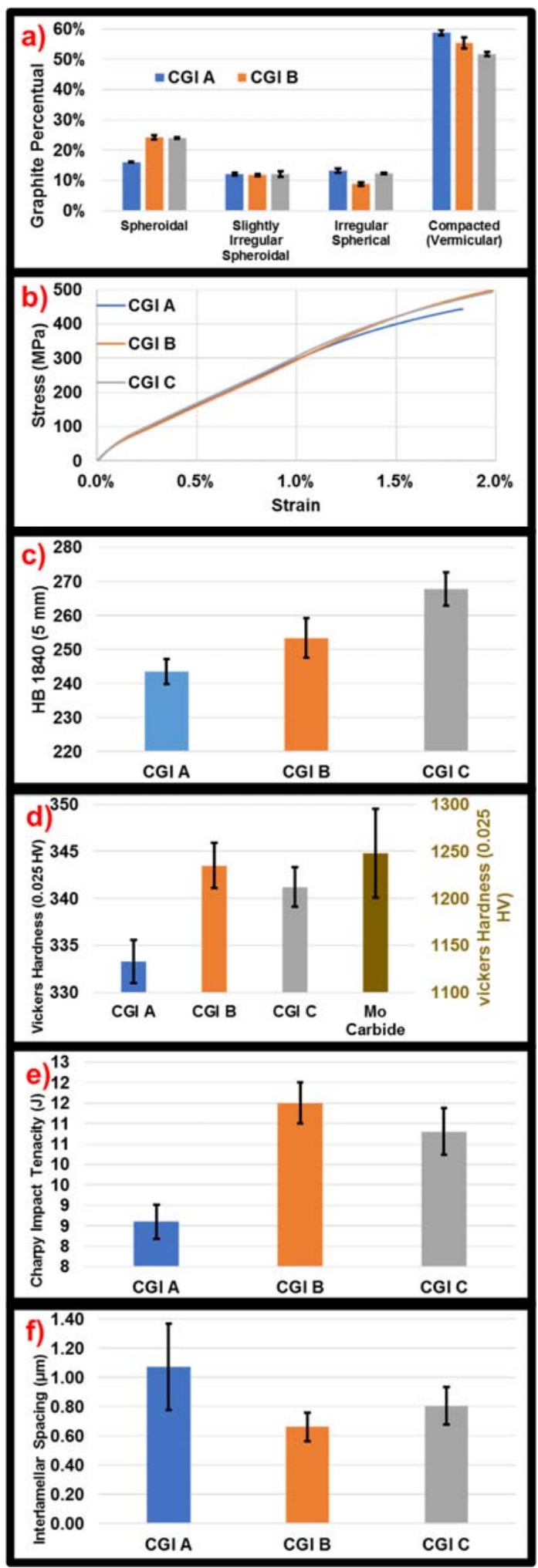

Figure 2. Mechanical and metallurgical properties of the materials evaluated. a) Shape of graphite; b) stress x strain curves; c) Brinell hardness; d) Vickers microhardness of matrix and molybdenum carbide; e) interlamellar spacing of the perlite; f) Charpy impact toughness. 
The milling experiments were made according to the parameters illustrated in Table 1, at a constant machining distance of $400 \mathrm{~mm}$, axial cutting depth of $1 \mathrm{~mm}$, and radial cutting depth of $10 \mathrm{~mm}$. To ensure reproducibility, three repetitions per condition were made. As cutting tools were used cemented carbide inserts, coated with TiAlN, manufactured by Walter Tools ${ }^{\circledR}$, with specification H3023018-10, with the geometries specified in Fig. 3. The tools were changed at each test, to avoid the effects of tool wear in the tribossystem.

Table 1. Machining parameters.

\begin{tabular}{ccc} 
Condition & $\mathrm{vc}(\mathrm{m} / \mathrm{min})$ & $\mathrm{f}(\mathrm{mm} / \mathrm{rev})$ \\
\hline 1 & 120 & 0.1 \\
2 & 120 & 0.2 \\
3 & 240 & 0.1 \\
\hline
\end{tabular}

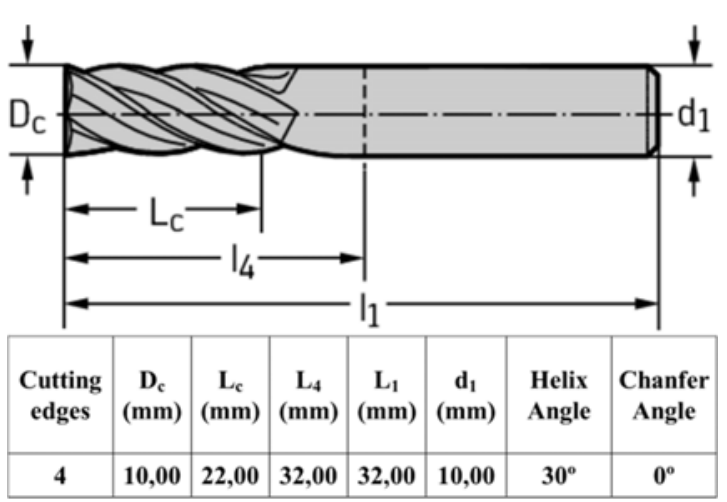

Figure 3. Geometric specifications of the cutting tool.

The experimental setup is illustrated in Fig. 4. The tests were carried out in a ROMI-Bridgeport Discovery ${ }^{\circledR} \quad 720 \quad \mathrm{CNC}$ machining center. The machining power was measured using a Kistler ${ }^{\circledR}$ platform model $9265 \mathrm{~B}$ at an acquisition rate of $1 \mathrm{kHz}$, and the machining power as calculated using equation 1. The machining temperature was measured using a FLIR ${ }^{\circledR}$ A3235 thermal camera, which was a resolution of 320x240 pixels, and a measuring range from 0-350 ${ }^{\circ} \mathrm{C}$, with an accuracy of $\pm 2{ }^{\circ} \mathrm{C}$, at an acquisition rate of 20 frames per second. The thermal camera emissivity was calibrated using T-type thermocouples and a Ni-9213 acquisition board manufactured by National Instruments ${ }^{\circledR}$, at an acquisition rate of $10 \mathrm{~Hz}$. The workpiece was sectioned in similar volumes to ensure similar contour conditions for each trial. After the tests, the surface roughness was measured using a surface profiler model S100 manufactured by Taylor Hobson ${ }^{\circledR}$, and the resulting machined surface was evaluated in relation to the average surface roughness (Ra). All the calibrations and test patterns were made according to the ones performed by da Silva et al. (2018).

$P_{c}=\frac{F_{r} v_{e}}{60 \eta}(W)$

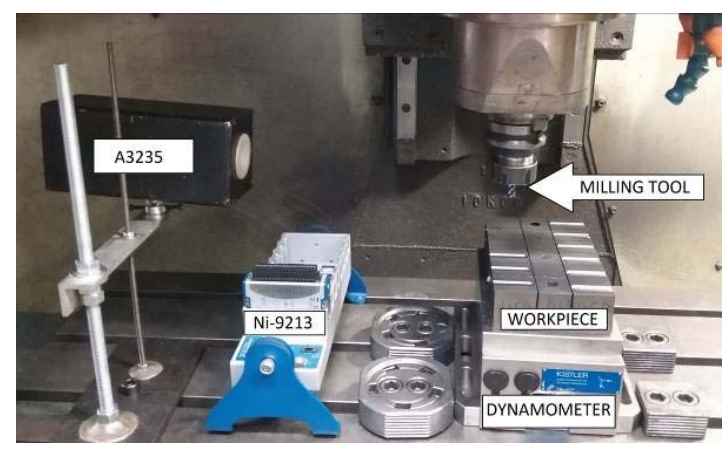

Figure 4. Experimental setup of the milling experiments. Adapted from (da Silva et al., 2018).

\section{RESULTS}

After the tests, the temperatures were correlated regarding the average results for each repetition of the frame high the highest temperature of each trial, as illustrated in Fig. 5, for each of the three conditions illustrated in Table 1, and materials illustrated in Fig. 1. In condition 2, the greater spread in temperature is caused by the higher feed rate, which generates more massive chips at each interaction between the tool and the workpiece.

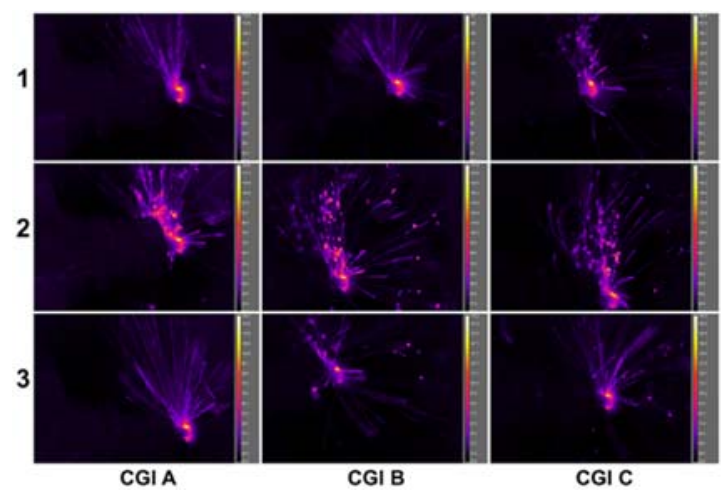

Figure 5. Frame with the highest temperature for each machining condition and material.

Figure 6 illustrates the average results for all the three cutting conditions (Table 1) in relation to each machined material (Fig. 1) for the machining temperature, power, and average surface roughness (Ra). Figure 6.a illustrates that the machining temperature and power increase from CGI A to CGI C. This is already expected, as illustrated in Fig. 2, which increases the mechanical properties in this same order. An overall positive correlation of $85 \%$ was found between these two variables. This correlation can be explained as more energy is required to shear the material, more energy will be dispersed in the form of heat. 
In contrast, the surface roughness in Fig. 6.b presented an inverse correlation of $-97 \%$. This inverse correlation can be explained as a more stable chip formation can be achieved as the mechanical properties of the material increase, mainly due to the graphite refinement in both CGIs B and C, as also observed by (Da Silva et al., 2020). Another possible explanation is that the lower machining temperatures resulted in more stiffness of the matrix during the shearing process, thus reducing the open grain phenomenon. According to Guesser et al. (2016), the biggest obstacle in achieving a better surface finish of all graphitic cast irons.

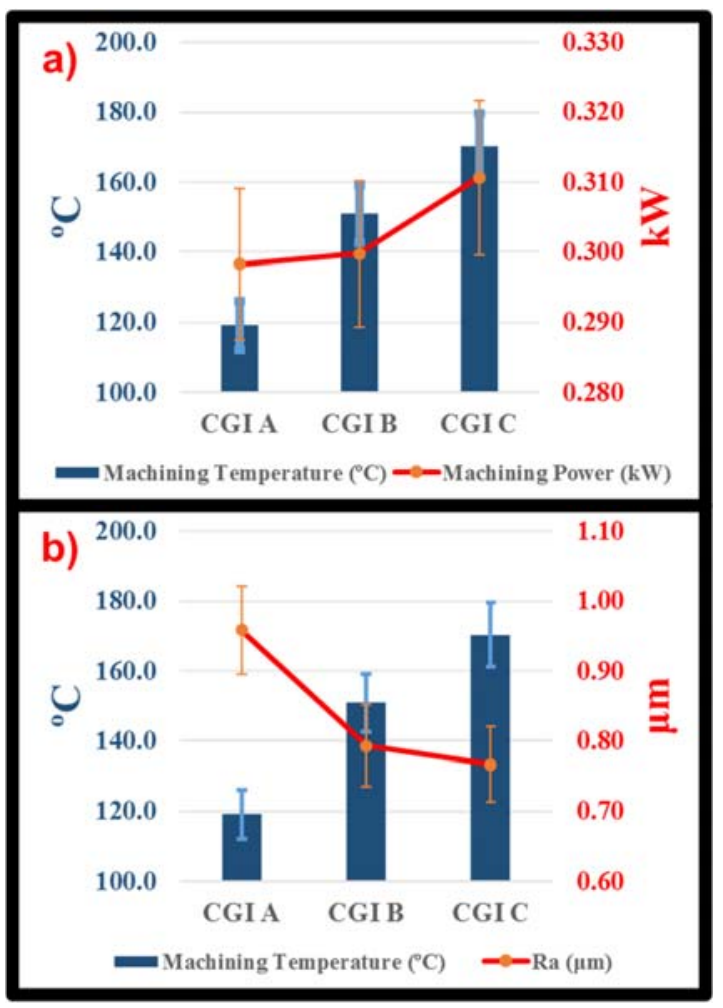

Figure 6. Comparison of the machining temperature with the a) machining power; b) Average surface roughness.

Figure 7 illustrates the Pearson correlation (Benesty et al., 2009) for each of the mechanical and metallurgical variables illustrated in Fig. 1, in relation to the machining temperature values illustrated in Fig. 6. This analysis is used to observe the "strength" of the correlation between two sets of data, for example, the hardness of each material and the average values of machining temperature, and to verify if this correlation is direct or inverse.

The spheroidal graphite is always present in CGI microstructure in concentrations up to $25 \%$ (Da Silva et al., 2019). As the rounder shape of the compacted graphite concentrates lower stresses, it tenacifies the matrix in relation to other graphite morphologies. Based on that, increasing the amount of spheroidal graphites leads to more energy being necessary to shear the material, and by consequence, more energy being dispersed in the form of heat. The inverse occurs for the compacted (vermicular) graphite, which presents more stress concentration points in relation to the spheroidal graphite, thus presenting an inverse correlation with the tenacity of the matrix, and by consequence, the machining temperature. The other forms of graphite are irregular forms (degenerations) between the spheroidal and vermicular graphite and thus less present in the overall pool of graphite in the matrix. This lower presence reflects the lower correlation between the slightly irregular spheroidal graphite and irregular spheroidal graphite with the machining temperature.

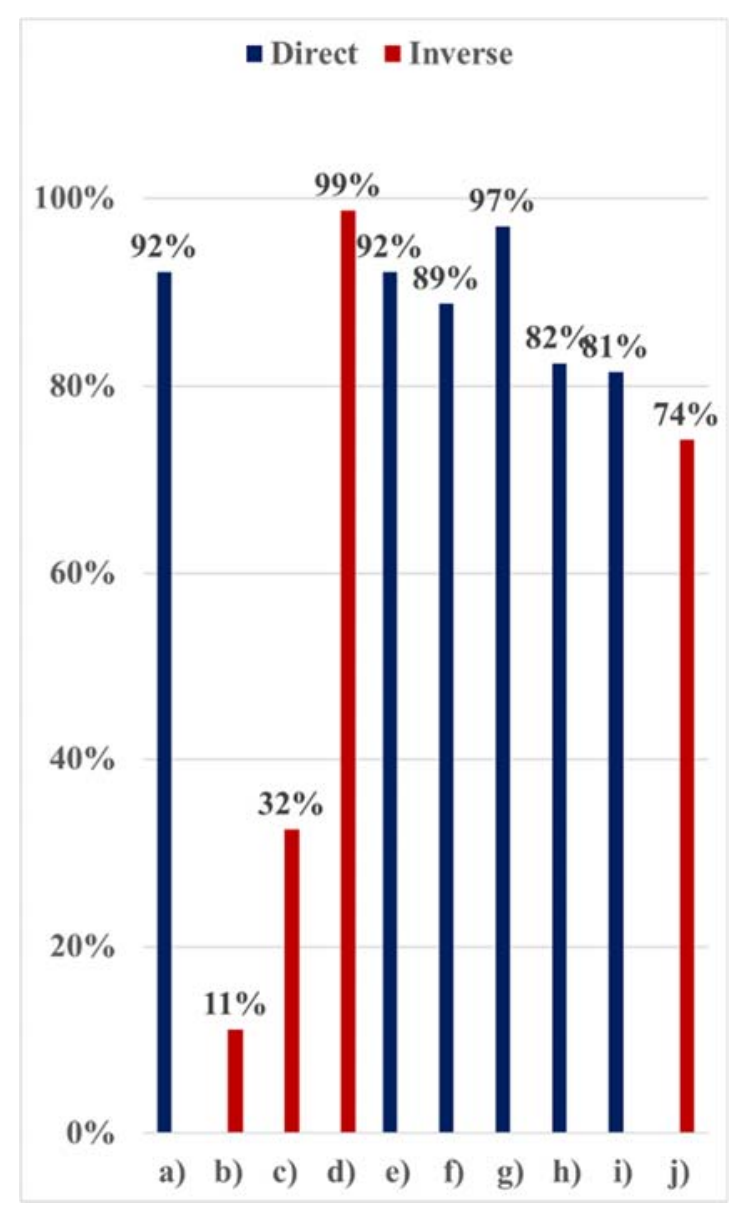

Figure 7. Correlation between the machining temperature and the mechanical and metallurgical variables illustrated in Fig. 2. a) Spheroidal Graphite $(\%)$, b) Slightly Irregular Spheroidal Graphite (\%), c) Irregular Spheroidal Graphite (\%), d) Compacted Graphite (Vermicular) (\%), e) Strain (\%), f) UTS (MPa), g) Brinell Hardness 1840 (5 mm), h) Vickers Hardness (0.025 HV), i) Charpy Impact Hardness (J),

j) Pearlite Interlamelar Spacing $(\mu \mathrm{m})$.

Both strain and ultimate tensile strength (UTS) obtained from the tensile tests (Fig 2.b) showed 
direct correlations with the machining temperature. Greater strain is an indicator of greater tenacity, and greater UTS is an indicator of a tougher material. The increasing of both properties leads to the necessity of more energy to shear the material, thus explaining more energy dispersed in the form of machining heat. Similarly, both Brinell macro hardness (HB) of the material and Vickers microhardness (HV) of the matrix presented direct correlations, as a harder material also requires more energy to cut. However, it is noteworthy that the Brinell micro hardness presented a stronger correlation in relation to the Vickers microhardness, as the HB represents the overall behavior of the material, both matrix, and graphite.

The Charpy impact energy and the pearlite interlamellar spacing presented the highest, respectively, direct and inverse correlations among the parameters with more than $70 \%$ of correlation. Greater impact energy can be correlated with more resistance to crack propagation and the need for more energy to machine the material. However, the Charpy impact energy test orders of magnitude lower to the shear rate of a machining process, thus explaining the lower than $90 \%$ correlation. The pearlite interlamellar spacing is an essential variable regarding the mechanical properties of an alloy mainly composed of ironcarbon. However, the lower mechanical properties of the graphite overshadow the influence of the interlamellar spacing, thus resulting in the correlation closer to $70 \%$.

\section{CONCLUSIONS}

This paper presented a study about the correlation of the machining temperature measured using a thermal camera and the mechanical and metallurgical variables of three grades of compacted graphite cast irons and the machining power and the surface roughness. Based on the results, the following conclusions can be drawn:

- The machining temperatures are directly correlated with the machining power and inversely correlated with the surface roughness;

- In general, only the spheroidal and compacted (vermicular) graphite morphologies can be correlated with the machining temperatures;

- The material's mechanical properties can be successfully correlated with the machining temperatures, as they dictated the amount of energy in the shearing process.

- Thermographic images can be successfully employed to monitor the relation between mechanical and metallurgical variables with the machinability of a system.
The authors are grateful to the Brazilian research agencies CNPq, FAPEMIG and Coordenação de Aperfeiçoamento de Pessoal de Nível Superior Brasil (CAPES) - Finance Code 001 for financial support, to Tupy S.A. for providing the work material and technical support and to Walter for the donation of the tooling.

\section{REFERENCES}

Benesty, J., Chen, J., Huang, Y., Cohen, I., 2009, Pearson correlation coefficient, Noise reduction in speech processing, Springer, pp. 1-4.

da Silva, L., Del Claro, V., Andrade, C., Guesser, W., Jackson, M., Machado, A., 2021. Tool wear monitoring in drilling of high-strength compacted graphite cast irons, Proceedings of the Institution of Mechanical Engineers, Part B: Journal of Engineering Manufacture 235, 207-218.

Da Silva, L., Ruzzi, R., Teles, V., Sales, W., Guesser, W., Machado, A., 2019, Analysis of the coefficient of friction at the workpiece-tool interface in milling of high strength compacted graphite cast irons. Wear 426, 1646-1657.

Da Silva, L., Souza, F., Guesser, W., Jackson, M., Machado, A., 2020, Critical assessment of compacted graphite cast iron machinability in the milling process. Journal of Manufacturing Processes 56, 63-74.

da Silva, L.R.R., Filho, A.F., Costa, E.S., Marcucci Pico, D.F., Sales, W.F., Guesser, W.L., Machado, A.R., 2018, Cutting Temperatures in End Milling of Compacted Graphite Irons. Procedia Manufacturing 26, 474-484.

Dawson, S., 2008, Compacted Graphite Iron - A Material Solution for Modern Diesel Engine Cylinder Blocks and Heads, 68 World Foundry Congress, Chennai, India, pp. 93-99.

Dawson, S., Indra, F., 2007, Compacted graphite iron-A new material for highly stressed cylinder blocks and cylinder heads, FORTSCHRITT BERICHTE-VDI REIHE 12 VERKEHRSTECHNIK FAHRZEUGTECHNIK 639, 181.

Dawson, S., Schroeder, T., 2004, Practical applications for compacted graphite iron. AFS transactions 47, 1-9.

Estes, J., Schneidewind, R., 1955, High strength cast iron produced by injection methods. Trans of AFS 103, 275.

Guesser, W.L., Duran, P., Krause, W., 2004, Compacted graphite iron for diesel engine cylinder blocks. Congrès Le diesel: aujourd'hui et demain Ecole centrale, 12-13.

Guesser, W.L., Guedes, L.C., 1997, Desenvolvimentos recentes em ferros fundidos aplicados à indústria automobilística, IX Simpósio de Engenharia Automotiva, AEA, São Paulo.

\section{ACKNOWLEDGEMENTS}


Guesser, W.L., Pereira, F.S., Boehs, L., 2016, Surface changes during turning of grey cast iron. International Journal of Machining and Machinability of Materials 18, 313-324.

ISO-945, 2011, Microstructure of cast irons Part 2:Graphite classification by image analysis.

ISO-16112, 2017, Compacted (vermicular) graphite cast irons - Classification.

Lim, C.-H., Goo, B.-C., 2011, Development of compacted vermicular graphite cast iron for railway brake discs. Metals and Materials International 17, 199-205.

Murthy, V., Seshan, S., 1985, Vermicular graphite cast iron-current state of the art. Sadhana 8, 361-372.

Shaw, M.C., 1984, Metal Cutting Principles, Clarendon Press.

Vander Voort, G.F., 1999. Metallography, principles and practice. ASM International. 